\title{
Effects of Naltrexone Alone and In Combination With Acamprosate on the Alcohol Deprivation Effect in Rats
}

\author{
Charles J Heyser*,', Kelly Moc', George F Koob ${ }^{2}$ \\ 'Franklin \& Marshall College, Department of Psychology, Lancaster, PA, USA; ${ }^{2}$ The Scripps Research Institute, Department of \\ Neuropharmacology, La Jolla, CA, USA
}

\begin{abstract}
Previous research in our laboratory has shown that responding for ethanol increases after a period of imposed deprivation during which no ethanol is available (the alcohol deprivation effect). This selective increase in responding for ethanol was blocked by chronic administration of acamprosate. In the present study the effects of naltrexone and the combination of naltrexone + acamprosate on oral ethanol self-administration were examined following an imposed period of abstinence. Male Wistar rats were trained to respond for ethanol $(10 \% \mathrm{w} / \mathrm{v})$ or water in a two-lever free-choice condition. After training, separate groups of rats received chronic injections $(2 \times /$ day $)$ of saline, naltrexone, or naltrexone + acamprosate during a 5 -day period of abstinence. Ethanol self-administration was tested in all groups of rats on the last day of abstinence, 30 min after the last drug injection. Responding for ethanol increased significantly following the deprivation period in animals treated with saline. Chronic administration of naltrexone and the combination naltrexone + acamprosate blocked the increased ethanol consumption following the imposed abstinence period on post-deprivation Day I. On post-deprivation Day 2, the combination of acamprosate with naltrexone blocked the rebound increase in ethanol consumption observed in animals treated with a low dose of naltrexone. These results support the hypothesis that naltrexone and acamprosate are effective in modulating aspects of alcohol-seeking behavior, and under certain situations may be more effective in combination.

Neuropsychopharmacology (2003) 28, |463-147I, advance online publication, 9 April 2003; doi:I 0.1038/sj.npp. 1300 I75
\end{abstract}

Keywords: ethanol, abstinence, alcohol deprivation effect, acamprosate, relapse, naltrexone

\section{INTRODUCTION}

Recently, several reviews have noted the critical need for examining the potential benefit of combination therapies, involving either multiple medications or the combination of medication with specific psychotherapies in the treatment of alcoholism (Kranzler, 2000). Two medications, naltrexone and acamprosate (calcium-acetyl homotaurinate), would appear to be ideal candidates for investigating the potential benefit of combined treatments, given that these pharmacotherapies have been used extensively in the treatment of alcoholism (see Garbutt et al, 1996; Litten et al, 1996; Mason and Ownby, 2000 for reviews of the clinical literature). An investigation of the combination of these two compounds is particularly intriguing given that these drugs have distinctly different neurochemical actions and, therefore, the combination may be more efficacious in treating alcoholism than either drug alone.

\footnotetext{
* Correspondence: Dr CJ Heyser, Franklin and Marshall College, Department of Psychology, P.O. Box 3003, Lancaster, PA 176043003, USA, Tel: + I 717291 3834, Fax: + | 717 29| 4387, E-mail: cheyser@fandm.edu

Received 21 June 2002; revised 27 January 2003; accepted 28 January 2003

Online publication: 03 February 2003 at http://www.acnp.org/citations/ Npp020303202/default.pdf
}

It is clear that endogenous opioid peptides play a key role in the reward pathways of ethanol as well as other drugs of abuse (Herz, 1997; Koob et al, 1998). Acute ethanol consumption or ethanol treatment in rodents has been reported to increase endorphin and enkephalin gene expression and increase opioid peptide release in the brain and pituitary (Wand, 1989; Angelogianni and Gianoulakis, 1993; Gianoulakis, 1996). Neurochemically, the opioid receptor antagonists naloxone and naltrexone are known to bind to all three opioid receptors (mu, delta, and kappa) as a function of the dose administered (Chang et al, 1979; Corbett et al, 1993). Animal studies have shown that the administration of naloxone and naltrexone decreases ethanol self-administration (see Ulm et al, 1995 for a review). This antagonist-induced decrease in ethanol intake has been observed in a wide variety of settings including home-cage drinking (Marfaing-Jallat et al, 1983; Reid and Hunter, 1984; Hubbell et al, 1986; Sandi et al, 1988; Froehlich et al, 1990) and operant paradigms (Samson and Doyle, 1985; Weiss et al, 1990; Hyytia and Sinclair, 1993; June et al, 1999).

Neurochemically, acamprosate is an analogue of amino acids found in brain, such as taurine and homocysteic acid (Dahchour and De Witte, 2000). Naassila et al (1998) and al Qatari et al (1998) have demonstrated that acamprosate binds to a specific spermidine-sensitive site that modulates 
the NMDA receptor in a complex way. Their work suggests that acamprosate acts as a 'partial coagonist' at the NMDA receptor, such that low concentrations enhance activation when receptor activity is low, and high concentrations inhibit activation when receptor activity is high. This may be particularly relevant to the success of acamprosate as a pharmacotherapy given that chronic exposure to ethanol results in an upregulation of NMDA receptors (Grant, 1990; Liljequist, 1991; Hoffman and Tabakoff, 1994) and an upregulation in the density of voltage-dependent calcium channels (Messing et al, 1986; Dolin et al, 1987; Dolin and Little, 1989; Whittington and Little, 1991). Acamprosate also promotes the release of taurine in the brain (Dahchour and de Witte, 2000). Taurine is a major inhibitory neuromodulator/neurotransmitter and an increase in taurine availability would also contribute to a decrease in hyperexcitability. Thus, each of these changes produced by acamprosate may contribute to the decreased hyperexcitability observed during ethanol withdrawal and abstinence (Dahchour et al, 1998). Therefore, it has been hypothesized that acamprosate may minimize or negate some of the physiological changes produced by chronic ethanol exposure (Popp and Lovinger, 2000).

Acamprosate has been shown to reduce ethanol consumption in rodents that have an extended history of ethanol exposure or are ethanol-dependent (Boismare et al, 1984; Le Magnen et al, 1987; Gewiss et al, 1991; Spanagel et al, 1996a; Hölter et al, 1997). It has also been shown to reduce the increased ethanol consumption associated with abstinence from ethanol (the alcohol deprivation effect) in rats (Hölter et al, 1997; Spanagel et al, 1996a; Heyser et al, 1998). In contrast, acamprosate appears to have less of an effect on baseline alcohol consumption in alcohol naïve and nondependent rats (Le Magnen et al, 1991; Heyser et al, 1998, Stromberg et al, 2001). Acamprosate also has been reported to attenuate some of the behavioral and neurochemical events associated with ethanol withdrawal (Dahchour and de Witte, 1999; Putzke et al, 1996; Cole et al, 2000). For example, acamprosate reduces the hyperactivity and elevated glutamate levels observed during the first $12 \mathrm{~h}$ of ethanol withdrawal (Dahchour and De Witte, 1999). However, not all aspects of withdrawal are reduced by acamprosate, such as withdrawal-induced hypothermia (Spanagel et al, 1996b).

The results of these studies show that naltrexone and acamprosate can modify ethanol consumption and that the effectiveness of these compounds may involve different neuropharmacological mechanisms. Therefore, it is possible that the drugs might be complementary (ie more efficacious) when administered in combination. In order to test this hypothesis, the present study was conducted to examine the effects of naltrexone alone or in combination with acamprosate on responding for ethanol after a period of abstinence using an operant model of alcohol-seeking behavior. An increase in ethanol consumption typically is observed after a period of abstinence in rats (Le Magnen, 1960; Sinclair and Senter, 1967, 1968; Wolffgramm and Heyne, 1995; Spanagel et al, 1996a; Heyser et al, 1997, 1998), monkeys (Kornet et al, 1990), and in human social drinkers (Burish et al, 1981). This effect has been termed the 'alcohol deprivation effect' (Sinclair and Senter, 1967). This model was selected for several reasons. First, this paradigm mimics the conditions under which these drugs are likely to be administered in human alcoholics, presumably after detoxification and in an alcohol-free state. Second, this is one of the few models that addresses the role of abstinence on potential subsequent drinking behavior. It has been proposed that a deprivation-induced increase in drinking may be related to 'loss of control', which may have implications for relapse (Wolffgramm and Heyne, 1995). Third, it has been reported previously that administration of acamprosate blocked the increased ethanol consumption typically observed in rats after an imposed abstinence period (Hölter et al, 1997; Spanagel et al, 1996a; Heyser et al, 1998). And fourth, intermittent treatment with naltrexone has been shown to attenuate moderately the alcohol deprivation effect (Hölter and Spanagel, 1999).

\section{MATERIALS AND METHODS}

\section{Subjects}

Subjects were 117 male Wistar rats (Charles River Laboratories, Hollister, CA). Rats were housed in groups of two per cage in a temperature- and humidity-controlled environment with a 12-h light/dark cycle (lights on at 10:00 pm). Food and water were available ad libitum, except as noted in the procedure. All procedures were conducted in accordance with the guidelines established by the National Institutes of Health Guide for the Care and Use of Laboratory Animals.

\section{Apparatus}

Ethanol self-administration training was conducted in standard operant chambers (Coulbourn Instruments, Allentown, PA) that were located in sound-attenuated, ventilated environmental cubicles. Two 35-ml syringes dispensed either ethanol or water through plastic tubing into two stainless-steel drinking cups mounted $4 \mathrm{~cm}$ above the grid floor and centered on the front panel of each chamber. Each drinking cup could hold approximately two reinforcer deliveries $(0.2 \mathrm{ml})$. Two retractable levers were located $4.5 \mathrm{~cm}$ to either side of the drinking cups. Fluid delivery and recording of operant responses were controlled by microcomputers.

\section{Procedure}

Operant procedure for oral ethanol self-administration training. All rats were trained to respond for ethanol or water in a two-lever free-choice situation. The procedure for induction of oral ethanol self-administration is a modification of Samson (1986) and has been successfully employed previously in our laboratory (Heyser et al, 1997, 1998). Rats were subjected to a 22-h water deprivation schedule only during the first 3 days of training (no ethanol was available during this period of training). Self-administration training was initiated in operant chambers by allowing rats to press either of two levers for a $0.2 \%(w / v)$ saccharin solution on a continuous reinforcement schedule $(0.1 \mathrm{ml}$ fluid/response) in 30-min daily sessions. After this initial training phase, and throughout the remainder of training and testing, water was freely available in the home cage. Starting on Day 4, rats 
were trained to alternate responding on the right and left lever (eg left, right, left, right, etc) in order to obtain a 5.0\% ethanol $+0.2 \%$ saccharin $(\mathrm{w} / \mathrm{v})$ solution. The alternation procedure was used to reduce positional (lever) biases in responding. Starting on Day 9 both levers were made available in a free-choice situation, with one lever producing an ethanol solution and the other lever producing water. During the next 10 days of training, ethanol concentrations were increased gradually to $8.0 \%$ and then to $10.0 \%$ ethanol $(\mathrm{w} / \mathrm{v})$. At the same time, saccharin concentrations were decreased to $0 \%$. The lever that produced ethanol continued to alternate from left to right on consecutive days throughout all training and testing to prevent establishment of a positional bias in responding. This procedure also maintains stable responding for both alcohol and water and permits a more stringent test of ethanol preference for animals, as the animals must track and respond to the appropriate lever necessary for obtaining ethanol. Rats were allowed to stabilize their intake of $10 \%$ ethanol (without saccharin) and water for 40-50 days and meet an established criterion for ethanol intake before being randomly assigned to the experimental groups. The criterion for stable responding was defined as $\pm 20 \%$ of the previous day's total number of responses for ethanol for three consecutive sessions. All testing and training were conducted during the animal's dark cycle.

Experiment 1: effects of chronic injections of naltrexone: After the establishment of stable responding for ethanol, a 5-day deprivation period was imposed during which time ethanol was not available. During this period of ethanol deprivation, rats remained in their home cages with food and water available ad libitum. Each animal received chronic (twice daily) subcutaneous (s.c.) injections of saline or naltrexone (dissolved in saline) for 5 days. Injections of saline or naltrexone $(0.005,0.01,0.06,0.125$, or $0.25 \mathrm{mg} / \mathrm{kg})$ were made at 12-h intervals at approximately 6:00 am and 6:00 pm $(n=7-8$ per group; total $n=45)$. Animals were tested $30 \mathrm{~min}$ after the last injection on Day 5 .

Experiment 2: effects of chronic injections of naltrexone and acamprosate: After the establishment of stable responding for ethanol, a 5-day deprivation period was imposed during which time ethanol was not available. Each animal received a s.c. injection of saline or naltrexone (dissolved in saline) followed immediately by an intraperitoneal (i.p.) injection of saline or acamprosate (dissolved in saline) twice daily during the 5 days of ethanol deprivation. The doses for the combined treatment of naltrexone/ acamprosate were: $0.005 / 25,0.005 / 100,0.01 / 25,0.01 / 100$, $0.06 / 25,0.06 / 100,0.125 / 25$, and $0.125 / 100 \mathrm{mg} / \mathrm{kg}$ (the dose of naltrexone is listed first; $n=8$ per group; total $n=72$ ). These doses were selected based on the results of the first experiment (chronic injections of naltrexone) and previous studies (Heyser et al, 1998). This range of doses includes doses that eliminate the ethanol deprivation effect and doses that are ineffective in order to assess additivity and to test for possible synergistic effects of these compounds. Injections were made at 12 -h intervals at approximately 6:00 am and 6:00 pm. Animals were tested $30 \mathrm{~min}$ after the last injection on Day 5.

\section{Data Analysis}

Statistical analyses were performed with the SPSS package for Windows version 8.0 (SPSS Inc., Chicago, IL). Results of the operant procedure are reported as the mean total number of bar presses for ethanol and water. Data for the number of bar presses for ethanol and water were analyzed by a mixed factor analysis of variance (ANOVA), with Dose as a between-subjects factor and Day of testing as a withinsubjects factor. Tukey's honestly significant difference tests and simple main effects analysis (Kirk, 1982) were used to determine the locus of significant main effects and interactions. A significance level of $p<0.05$ was used for all statistical analyses.

\section{RESULTS}

\section{Experiment 1}

The ANOVA conducted on the total number of bar presses for ethanol revealed a significant main effect of Day $\mathrm{F}(2,78)=10.24, p<0.05$, along with a significant Day$\times$ Treatment interaction $\mathrm{F}(10,78)=8.91, p<0.05$. As can be seen in Figure 1 (top panel), animals treated with saline or 0.005 and $0.01 \mathrm{mg} / \mathrm{kg}$ naltrexone and deprived of ethanol for 5 days significantly increased their responding for ethanol compared to baseline levels of responding on the first day post-deprivation (for saline animals: mean baseline intake $=0.67 \mathrm{~g} / \mathrm{kg}$ and mean post-deprivation Day $1=1.13 \mathrm{~g} / \mathrm{kg}$ ). In contrast, no increase in responding for ethanol was observed in animals chronically treated with $0.06,0.125$, or $0.25 \mathrm{mg} / \mathrm{kg}$ naltrexone. Furthermore, responding for ethanol was significantly decreased in animals treated with 0.125 and $0.25 \mathrm{mg} / \mathrm{kg}$ naltrexone on the first day post-deprivation. Responding for ethanol returned to baseline levels on the next day (second day post-deprivation) in these two groups. In contrast, animals treated with $0.06 \mathrm{mg} / \mathrm{kg}$ naltrexone significantly increased responding for ethanol on the second day post-deprivation compared to baseline levels. The effects of ethanol deprivation and naltrexone were selective for ethanol, and no significant alterations in responding for water were observed (see Figure 1, bottom panel).

To examine the time course of responding for ethanol, cumulative response records were generated (see Figure 2). As previously observed in our laboratory, animals generally make most of their responses for ethanol in the first 1015 min of the session. A similar pattern of responding was observed in deprived animals during the first $10 \mathrm{~min}$, and this pattern did not differ from baseline responding (see Figure 2). However, animals treated with saline or 0.005 and $0.01 \mathrm{mg} / \mathrm{kg}$ naltrexone during the 5-day period of ethanol deprivation continued to respond for ethanol throughout the 30-min session. This increased responding in the latter stages of the session was eliminated in animals chronically treated with $0.06 \mathrm{mg} / \mathrm{kg}$ naltrexone during the deprivation period. Interestingly, these animals significantly increased responding for ethanol on the second day post-deprivation compared to baseline levels. Animals treated with higher doses of naltrexone $(0.125$ and $0.25 \mathrm{mg} / \mathrm{kg})$ significantly reduced responding for ethanol below baseline levels. Although total responding for ethanol was reduced in 

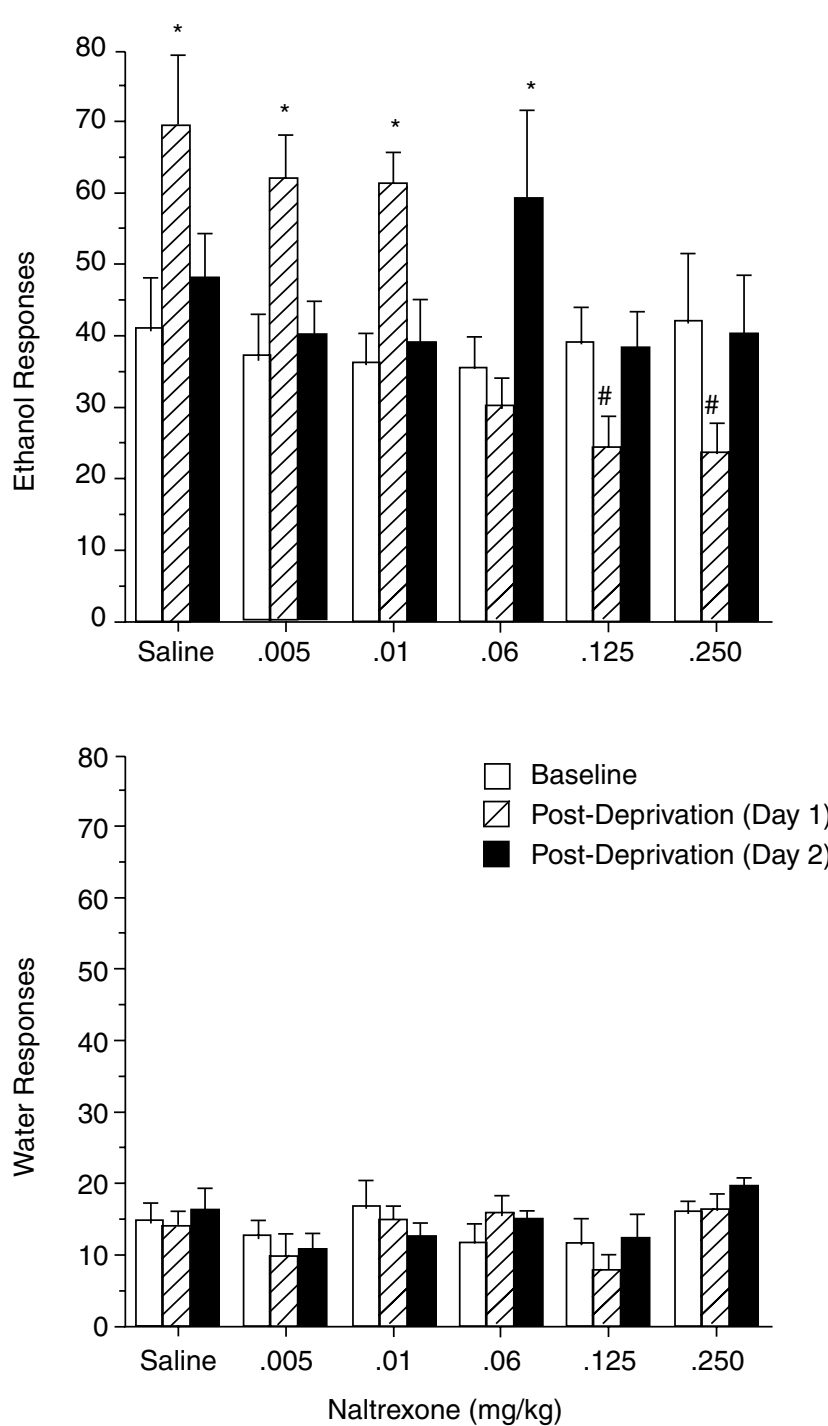

Figure I Effects of chronic administration of saline or naltrexone on responding for ethanol (top panel) or water (bottom panel) after 5 days of ethanol deprivation. Ethanol responding increased above baseline after 5 days of ethanol deprivation in animals treated with saline. Chronic administration of naltrexone eliminated the ethanol deprivation effect without affecting water responding. Data are presented as mean total responses $+\mathrm{SE}$. * Indicates significantly greater than baseline responding $(p<0.05)$. Indicates significantly lower than baseline responding $(p<0.05)$.

animals chronically treated with 0.125 or $0.25 \mathrm{mg} / \mathrm{kg}$ naltrexone, initial responding for ethanol was unaffected (see Figure 2). Therefore, in terms of the cessation of responding, administration of either 0.125 or $0.25 \mathrm{mg} / \mathrm{kg}$ naltrexone resulted in an earlier termination of responding compared to animals that received saline.

\section{Experiment 2}

The ANOVA conducted on the number of responses for ethanol revealed a significant main effect of Day $\mathrm{F}(2,126)=6.71, p<0.05$, along with a significant Day$\times$ Treatment interaction $\mathrm{F}(16,126)=5.23, p<0.05$. As can be seen in Figures 3 and 4, animals treated with saline, $0.005 / 25$, and $0.01 / 25 \mathrm{mg} / \mathrm{kg}$ (naltrexone + acamprosate) during the 5-day ethanol deprivation period significantly increased their responding for ethanol compared to baseline levels of responding on the first day post-deprivation. In contrast, no increase in responding for ethanol was observed in animals chronically treated with $0.005 / 100$, $0.01 / 100,0.06 / 25$, and $0.06 / 100 \mathrm{mg} / \mathrm{kg}$ (naltrexone + acamprosate) on the first day post-deprivation. Furthermore, responding for ethanol was significantly decreased below baseline in animals treated with $0.125 / 25$ and $0.125 / 100 \mathrm{mg} /$ $\mathrm{kg}$ (naltrexone + acamprosate). The deprivation-induced increase in responding for ethanol was transient as all animals returned to baseline levels of responding on the second day post-deprivation. Further examination of cumulative response curves for ethanol revealed almost identical patterns of responding as that seen after the administration of naltrexone (see Figure 2) or acamprosate (see Heyser et al, 1998) given alone (data not shown). The effects of ethanol deprivation and drug treatment were selective for ethanol, and no significant alterations in responding for water were observed (see Figures 3 and 4).

\section{DISCUSSION}

In the present study, increased responding for ethanol was observed after a period of deprivation compared to baseline levels of ethanol intake, confirming previous demonstrations of the alcohol deprivation effect (Le Magnen, 1960; Sinclair and Senter, 1967, 1968; Wolffgramm and Heyne, 1995; Spanagel et al, 1996a; Heyser et al, 1997). Chronic administration of naltrexone alone or in combination with acamprosate eliminated this deprivation-induced increase in drinking. These results confirm previous reports that opiate antagonists and acamprosate reduce the alcohol deprivation effect (Hölter et al, 1997; Spanagel et al, 1996a; Heyser et al, 1998; Hölter and Spanagel, 1999; Hölter et al, 2000). In the present study, the effects of drug administration had no effects on responding for water. Taken together with previous reports, these results provide further support for the effectiveness of each compound in modulating some aspects of alcohol-seeking behavior.

Chronic administration of naltrexone eliminated the ethanol deprivation effect and significantly decreased responding for ethanol at higher doses. These results confirm previous reports that opioid receptor antagonists reduce ethanol intake (Samson and Doyle, 1985; Hubbell et al, 1986; Froehlich et al, 1990; Weiss et al, 1990; Hyytia and Sinclair, 1993; June et al, 1999) and attenuate the ethanol deprivation effect (Hölter and Spanagel, 1999; Hölter et al, 2000). The reduction in responding for ethanol below baseline observed after administration of the higher doses $(0.125$ and $0.25 \mathrm{mg} / \mathrm{kg})$ of naltrexone was specific to the first day after ethanol deprivation. Responding for ethanol in these treatment groups returned to baseline levels on the following day and remained stable across subsequent test days. Interestingly, the animals receiving $0.06 \mathrm{mg} / \mathrm{kg}$ naltrexone did not show an increase in drinking after the period of abstinence on the day ethanol was first made available (ie maintaining baseline levels of responding for ethanol). However, an increase in responding above baseline levels was observed the following day (postdeprivation Day 2). This may represent a rebound or delayed ethanol deprivation effect. This rebound may be 

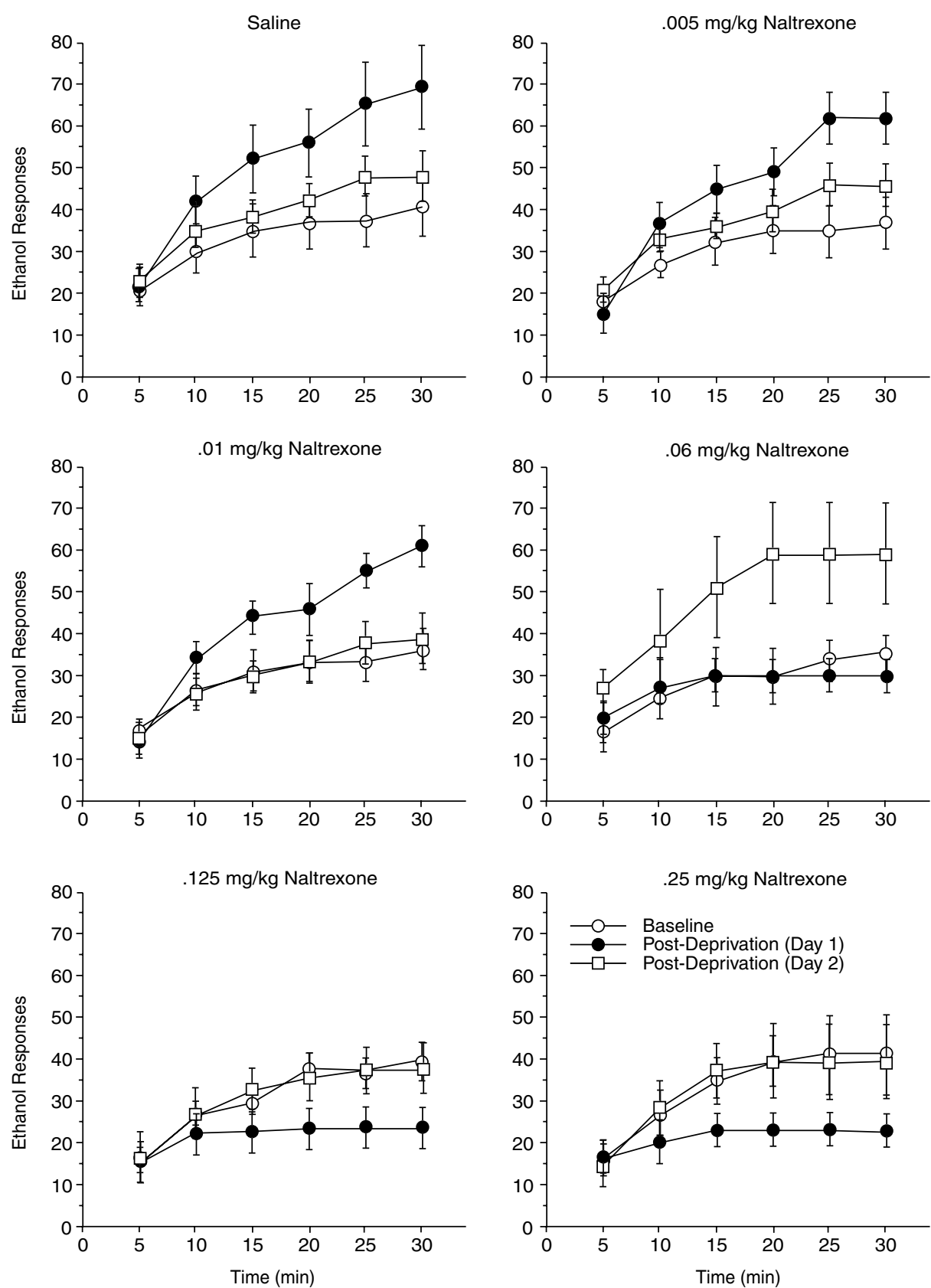

Figure 2 Effects of chronic administration of saline or naltrexone on responding for ethanol after 5 days of ethanol deprivation. Mean cumulative responses for ethanol in 5-min intervals during baseline (open circles), I day post-deprivation (closed circles), and the second day post-deprivation (open squares). Each panel represents a different treatment. Ethanol responding increased above baseline after 5 days of ethanol deprivation in animals treated chronically with saline. Chronic administration of naltrexone eliminated the deprivation-induced increases in ethanol responding. Data are presented as mean + SE.

due to the apparent threshold nature of this dose (still lower doses were without effect) and the fact that naltrexone treatments had been discontinued (ie the last injection of naltrexone was given $\sim 24 \mathrm{~h}$ prior to the second day postdeprivation).

The decrease in responding for ethanol after the administration of naltrexone was not immediate. All animals responded for ethanol within $30 \mathrm{~s}$ of the start of each session, regardless of drug administration. In addition, all groups initiated responding for ethanol and showed similar rates of responding during the first minutes of the operant session. Therefore, the blockade of opioid receptors does not seem to affect the onset of responding for ethanol, but results in the early cessation of responding in this limited-access setting. These data confirm several previous reports in animals that showed a delayed effect of opioid antagonists to affect ethanol intake (Hubbell et al, 1986; Hyytia and Sinclair, 1993; Slawecki et al, 1997; Heyser et al, 1999).

Chronic administration of naltrexone and acamprosate in combination resulted in an elimination of the alcohol deprivation effect. However, there was little evidence of any 

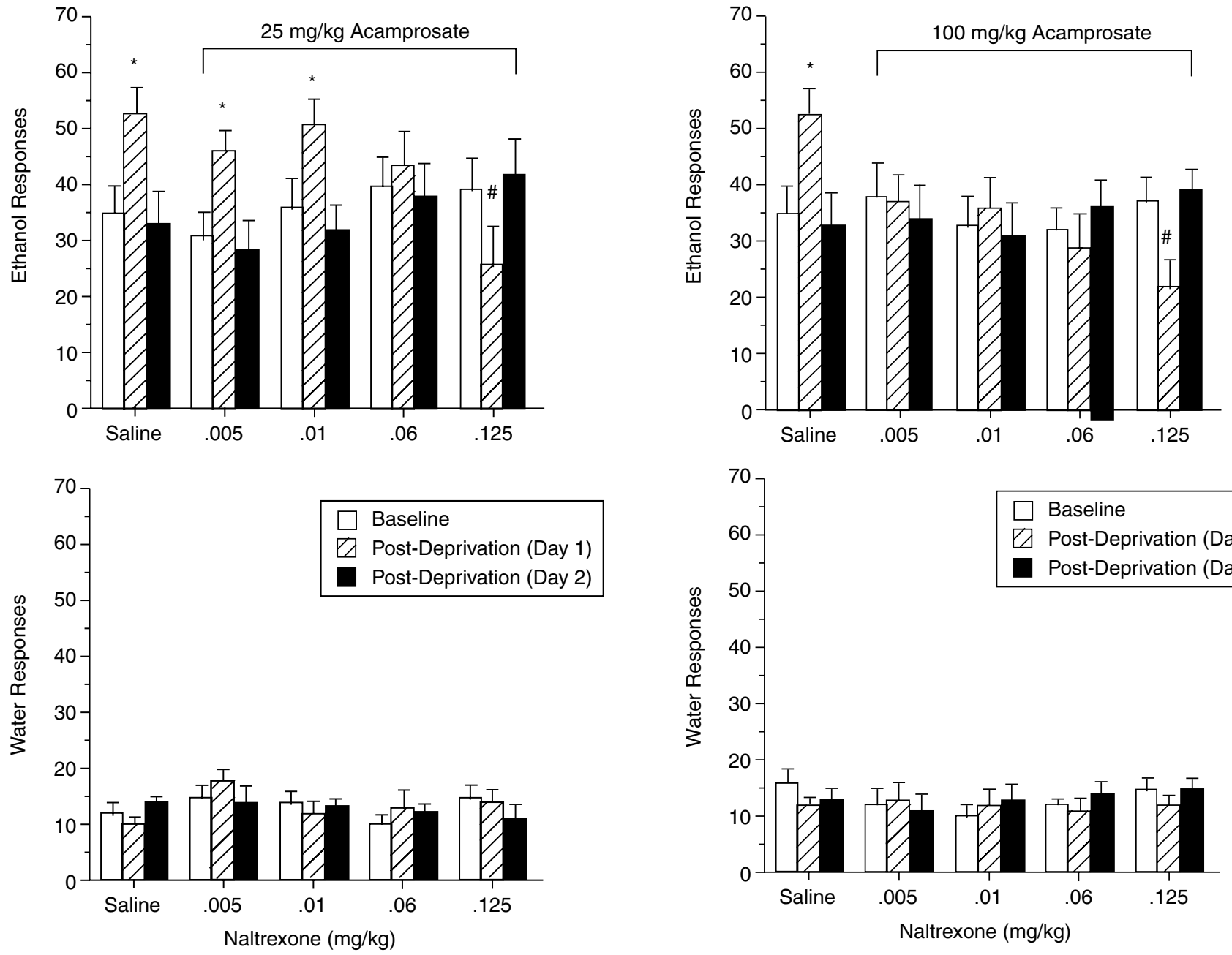

Figure 3 Effects of chronic administration of saline or the combination of naltrexone $+25 \mathrm{mg} / \mathrm{kg}$ acamprosate on responding for ethanol (top panel) and water (bottom panel) after 5 days of ethanol deprivation. Ethanol responding increased above baseline after 5 days of ethanol deprivation in animals treated with saline, $0.005 \mathrm{mg} / \mathrm{kg}$ naltrexone + acamprosate, and $0.01 \mathrm{mg} / \mathrm{kg}$ naltrexone + acamprosate. Chronic administration of higher doses of naltrexone and acamprosate eliminated the ethanol deprivation effect without affecting water responding. Data are presented as mean total responses $+\mathrm{SE}$. *Indicates significantly greater than baseline responding $(p<0.05)$. Indicates significantly lower than baseline responding $(p<0.05)$.

additive or synergistic effects of this combination on responding for ethanol on post-deprivation Day 1. More specifically, the administration of combinations including either $0.06 \mathrm{mg} / \mathrm{kg}$ naltrexone or $100 \mathrm{mg} / \mathrm{kg}$ acamprosate reduced the ethanol deprivation effect, and combinations including the higher dose of naltrexone $(0.125 \mathrm{mg} / \mathrm{kg})$ further reduced responding for ethanol below baseline levels. These data replicate Experiment 1 in the present study (effects of chronic injections of naltrexone) and confirm our previous report showing the elimination of the ethanol deprivation effect after the administration of $100 \mathrm{mg} / \mathrm{kg}$ acamprosate, but not after the administration of $25 \mathrm{mg} / \mathrm{kg}$ acamprosate (Heyser et al, 1998). Thus, the effects of these combined administrations on responding for ethanol are similar to those observed after the administration of either drug alone. Although acamprosate alone did

not affect baseline responding for ethanol in this limited access paradigm (Heyser et al, 1998), there are reports showing a reduced consumption of ethanol after the administration of acamprosate (Boismare et al, 1984; Le Magnen et al, 1987; Spanagel et al, 1996a). However, rats in these studies were dependent on ethanol (Le Magnen et al, 1987) or selected for high ethanol intake (Boismare et al, 1984) or had an extensive history of ethanol consumption (24-h access to bottles of ethanol for 8 months) (Spanagel et al, 1996a). In contrast, animals in the present study were only trained to stable baseline (about 3-4 months) and in a limited access paradigm (30 min/day). Therefore, the effectiveness of acamprosate in reducing ethanol consumption appears to be related to ethanol preference and/or history (see Heyser et al, 1998 for discussion). This hypothesis is supported by a recent study by Stromberg 
et al (2001) that showed relatively little effect of acamprosate on baseline responding for ethanol. These authors also reported no synergistic or additive effects of the coadministration of acamprosate and naltrexone on baseline responding for ethanol.

The guiding hypothesis being tested in the current study was that the administration of naltrexone in combination with acamprosate would be more effective in modulating responding for ethanol than either drug given alone. This hypothesis was based on a number of empirical findings. First, these drugs have been shown to significantly reduce the rate of relapse in alcohol-dependent humans (see Garbutt et al, 1999; Litten et al, 1996; Mason and Ownby, 2000; for reviews of the clinic literature), despite the fact that these drugs work through different neurochemical mechanisms. Second, it has been hypothesized that naltrexone has a more direct effect on the positive reinforcing action of ethanol given that naltrexone decreases ethanol consumption in a variety of animal models (Samson and Doyle, 1985; Hubbell et al, 1986; Froehlich et al, 1990; Weiss et al, 1990; Hyytia and Sinclair, 1993; June et al, 1999). In contrast, the effectiveness of acamprosate on ethanol consumption appears to be dependent on the history of ethanol exposure. Acamprosate, unlike naltrexone, has been shown to reduce some of the symptoms of ethanol withdrawal (Dahchour and de Witte, 1999; Putzke et al, 1996; Cole et al, 2000). For example, in a recent report, Cole et al (2000) showed that acamprosate, but not naltrexone, inhibited conditioned abstinence behaviors. Taken together, this combination of drug therapies would seem ideal in the sense that acamprosate and naltrexone target aspects of both positive and negative reinforcement. However, there was little evidence of any additive or synergistic effects of this combination on responding for ethanol on post-deprivation Day 1.

Given this lack of additivity, it would appear from these data that acamprosate and naltrexone are working on parallel neuronal systems. Unfortunately, it is not possible at this time to fully describe the neuronal mechanisms responsible for the alcohol deprivation effect. The neuronal mechanisms are likely to be complex given the multiple actions of ethanol in the central nervous system and the fact that these systems may be (and often are) altered by the history of ethanol exposure. For example, chronic exposure to ethanol results in an upregulation of NMDA receptors (Grant, 1990; Liljequist, 1991; Hoffman and Tabakoff, 1994) and an upregulation in the density of voltage-dependent calcium channels (Messing et al, 1986; Dolin et al, 1987; Dolin and Little, 1989; Whittington and Little, 1991). More recently, Rasmussen et al (2002) has reported that mediobasal hypothalamus pro-opiomelanocortin (POMC) mRNA concentrations were decreased after chronic ethanol consumption. In contrast, an increase in forebrain POMC mRNA was observed after a period of ethanol deprivation (abstinence). Therefore, changes in the endogenous opioid systems are observed in response to the presence of ethanol and its subsequent removal. It is clear from other reports that these neuroadaptations are not limited to these systems and include alterations in serotonergic (McBride, Le, and Noronha, 2002) and dopaminergic (Bailey et al, 2001) function. These results illustrate the need for further research into these neuronal mechanisms. Furthermore, although the data from the present study failed to show a benefit from a combined treatment strategy on the acute alcohol deprivation effect using a limited access operant paradigm, caution should be taken in terms of generalizing these results to other experimental situations that include aspects of ethanol dependence and protracted abstinence (see Roberts et al, 2000).

\section{ACKNOWLEDGEMENTS}

This research was supported by grants from the National Institute on Alcohol Abuse and Alcoholism AA08459 and AA06420 (George F Koob, PhD), AA05403 (Charles J Heyser, $\mathrm{PhD}$ ), and Groupe LIPHA (George F Koob, PhD). This is publication number 14167-NP from the Scripps Research Institute. Preliminary data were discussed by Charles J Heyser $(\mathrm{PhD})$ at the Research Society on Alcoholism Annual Meeting in Denver, CO, June 2000. We thank Mike Arends for his help in editing this manuscript.

\section{REFERENCES}

Angelogianni P, Gianoulakis C (1993). Chronic ethanol increases proopiomelanocortin gene expression in the rat hypothalamus. Neuroendocrinology 57: 106-114.

Bailey CP, O'Callaghan MJ, Croft AP, Manley SJ, Little HJ (2001). Alterations in mesolimbic dopamine function during the abstinence period following chronic ethanol consumption. Neuropharmacology 41: 989-999.

Boismare F, Daoust M, Moore N, Saligaut C, Lhuintre JP, Chretien $\mathrm{P}$ et al (1984). Homotaurine derivative reduces the voluntary intake of ethanol by rats: are cerebral GABA receptors involved. Pharmacol Biochem Behav 22: 787-789.

Burish TG, Maisto SA, Cooper AM, Sobell MB (1981). Effects of voluntary short-term abstinence from alcohol on subsequent drinking patterns of college students. J Stud Alcohol 42: 1013-1020.

Chang K-J, Cooper BR, Hazum E, Cuatrecasas P (1979). Multiple opiate receptors: different regional distribution in the brain and differential binding of opiates and opioid peptides. $\mathrm{Mol}$ Pharmacol 16: 91-104.

Cole JC, Littleton JM, Little HJ (2000). Acamprosate, but not naltrexone, inhibits conditioned abstinence behaviour associated with repeated ethanol administration and exposure to a plusmaze. Psychopharmacology 147: 403-411.

Corbett AD, Paterson SL, Kosterlitz HW (1993). Selectivity of ligands for opioid receptors. In: Herz A (ed). Opioids I (Handbook of Experimental Pharmacology Series Vol 104). Springer-Verlag: New York. pp 645-679.

Dahchour A, de Witte P (1999). Acamprosate decreases the hypermotility during repeated ethanol withdrawal. Alcohol 18: 77-81.

Dahchour A, de Witte P (2000). Ethanol and amino acids in the central nervous system: assessment of the pharmacological actions of acamprosate. Prog Neurobiol 60: 343-362.

Dahchour A, de Witte P, Bolo N, Nedelec J-F, Muzet M, Durbin P et al (1998). Central effects of acamprosate: part 1. Acamprosate blocks the glutamate increase in the nucleus accumbens microdialysate in ethanol withdrawn rats. Psychiatry Res 82: 107-114.

Dolin SJ, Little HJ (1989). Are changes in neuronal calcium channels involved in ethanol tolerance. JPET 250: 985-991.

Dolin S, Little H, Hudspith M, Pagonis C, Littleton J (1987). Increased dihydropyridine-sensitive calcium channels in rat 
brain may underlie ethanol physical dependence. Neuropharmacology 26: 275-279.

Froehlich JC, Harts J, Lumeng L, Li T-K (1990). Naloxone attenuates voluntary ethanol intake in rats selectively bred for high ethanol preference. Pharmacol Biochem Behav 35: 385-390.

Garbutt JC, West SL, Carey TS, Lohr KN, Crews FT (1999). Pharmacological treatment of alcohol dependence-a review of the evidence. JAMA 281: 1318-1325.

Gewiss M, Heidbreder C, Opsomer L, Durbin P, De Witte P (1991). Acamprosate and diazepam differentially modulate alcoholinduced behavioural and cortical alterations in rats following chronic inhalation of ethanol vapour. Alcohol Alcohol 26: 129-137.

Gianoulakis C (1996). Implications of endogenous opioids and dopamine in alcoholism: human and basic science studies. Alcohol Alcohol 31: 33-42.

Grant KA (1990). Ethanol withdrawal seizures and the NMDA receptor complex. Eur J Pharmacol 176: 289-296.

Herz A (1997). Endogenous opioid systems and alcohol addiction. Psychopharmacology 129: 99-111.

Heyser CJ, Roberts AJ, Schulteis G, Koob GF (1999). Central administration of an opiate antagonist decreases oral ethanol self-administration in rats. Alcohol Clin Exp Res 23: 1468-1476.

Heyser CJ, Schulteis G, Durbin P, Koob GF (1998). Chronic acamprosate eliminates the alcohol deprivation effect while having limited effects on baseline responding for ethanol in rats. Neuropsychopharmacology 18: 125-133.

Heyser CJ, Schulteis G, Koob GF (1997). Increased ethanol selfadministration after a period of imposed ethanol deprivation in rats trained in a limited access paradigm. Alcohol Clin Exp Res 21: 784-791.

Hoffman PL, Tabakoff B (1994). The role of the NMDA receptor in ethanol withdrawal. Experientia 71: 61-70.

Hölter SM, Henniger MSH, Lipkowski AW, Spanagel R (2000). Kappa-opioid receptors and relapse-like drinking in long-term ethanol-experienced rats. Psychopharmacology 153: 93-102.

Hölter SM, Landgraf R, Zieglansberger W, Spanagel R (1997). Time course of acamprosate action on operant ethanol self-administration after ethanol deprivation. Alcohol Clin Exper Res 21: 862-868.

Hölter SM, Spanagel R (1999). Effects of opiate antagonist treatment on the alcohol deprivation effect in long-term ethanol-experienced rats. Psychopharmacology 145: 360-369.

Hubbell CL, Czirr SA, Hunter GA, Beaman CM, LeCann NC, Reid LD (1986). Consumption of ethanol solution is potentiated by morphine and attenuated by naloxone persistently across repeated daily administrations. Alcohol 3: 39-54.

Hyytia P, Sinclair JD (1993). Responding for oral ethanol after naloxone treatment by alcohol-preferring AA rats. Alcohol Clin Exp Res 17: 631-636.

June HL, McCane SR, Zink RW, Portoghese PS, Li TK, Froehlich JC (1999). The delta(2)-opioid receptor antagonist naltriben reduces motivated responding for ethanol. Psychopharmacology 147: 81-89.

Kirk RE (1982). Experimental Design: Procedures for the Behavioral Sciences, 2nd edn. Brooks/Cole: Belmont, CA.

Koob GF, Roberts AJ, Schulteis G, Parsons LH, Heyser CJ, Hyytia P et al (1998). Neurocircuitry targets in ethanol reward and dependence. Alcohol Clin Exp Res 22: 3-9.

Kornet M, Goosen C, Van Ree JM (1990). The effect of interrupted alcohol supply on spontaneous alcohol consumption by rhesus monkeys. Alcohol Alcohol 25: 407-412.

Kranzler HR (2000). Pharmacotherapy of alcoholism: gaps in knowledge and opportunities for research. Alcohol Alcohol 35: 537-547.

Le Magnen J (1960). Etude de quelques facteurs associé à des modification de la consommation spontanée d'alcool éthylique par le rat. J Physiol (Paris) 52: 873-884.
Le Magnen J, Tran G, Durlach J, Martin C (1987). Dose-dependent suppression of the high alcohol intake of chronically intoxicated rats by Ca-acetyl homotaurinate. Alcohol 4: 97-102.

Liljequist S (1991). The competitive NMDA receptor antagonist CGP 39551 inhibits ethanol withdrawal seizures. Eur J Pharmacol 192: 197-198.

Litten RZ, Allen J, Fertig J (1996). Pharmacotherapies for alcohol problems: a review of research with focus on developments since 1991. Alcohol Clin Exp Res 20: 859-876.

Marfaing-Jallat P, Miceli D, LeMagnen J (1983). Decrease in ethanol consumption by naloxone in naïve and dependent rats. Pharmacol Biochem Behav 18: 537-539.

Mason BJ, Ownby RL (2000). Acamprosate for the treatment of alcohol dependence: a review of double-blind, placebo-controlled trials. CNS Spectrums 5: 58-69.

McBride WJ, Le A-D, Noronha A (2002). Central nervous system mechanisms in alcohol relapse. Alcohol Clin Exp Res 26: 280-286.

Messing RO, Carpenter CL, Diamond I, Greenberg DA (1986). Ethanol regulates calcium channels in clonal neural cells. Proc Natl Acad Sci USA 83: 6213-6215.

Naassila M, Hammoumi S, Legrand E, Durbin P, Daoust M (1998). Mechanism of action of acamprosate: part I. Characterization of spermidine-sensitive acamprosate binding site in rat brain. Alcohol Clin Exper Res 22: 802-809.

Popp RL, Lovinger DM (2000). Interaction of acamprosate with ethanol and spermine on NMDA receptors in primary cultured neurons. Eur J Pharmacol 394: 221-231.

Putzke J, Spanagel R, Tölle TR, Zieglgänsberger W (1996). The anti-craving drug acamprosate reduces c-fos expression in rats undergoing ethanol withdrawal. Eur J Pharmacol 317: 39-48.

al Qatari M, Bouchenafa O, Littleton J (1998). Mechanism of action of acamprosate: part II. Ethanol dependence modifies effects of acamprosate on NMDA receptor binding in membranes from rat cerebral cortex. Alcohol Clin Exp Res 22: 810-814.

Rasmussen DD, Boldt BM, Wilkinson CW, Mitton DR (2002). Chronic daily ethanol and withdrawal: 3. Forebrain proopiomelanocortin gene expression and implications for dependence, relapse, and deprivation effect. Alcohol Clin Exp Res 26: 535-546.

Reid LD, Hunter GA (1984). Morphine and naloxone modulate intake of ethanol. Alcohol 1: 33-37.

Roberts AJ, Heyser CJ, Cole M, Griffin P, Koob GF (2000). Excessive ethanol drinking following a history of dependence: animal model of allostasis. Neuropsychopharmacology 22: 581-594.

Samson HH (1986). Initiation of ethanol reinforcement using a sucrose-substitution procedure in food- and water-sated rats. Alcohol Clin Exp Res 10: 436-442.

Samson HH, Doyle TF (1985). Oral ethanol self-administration in the rat: effects of naloxone. Pharmacol Biochem Behav 22: 91-99.

Sandi C, Borrell J, Guaza C (1988). Naloxone decreases ethanol consumption within a free choice paradigm in rats. Pharmacol Biochem Behav 29: 39-43.

Sinclair JD, Senter RJ (1967). Increased preference for ethanol in rats following alcohol deprivation. Psychon Sci 8: 11-12.

Sinclair JD, Senter RJ (1968). Development of an alcoholdeprivation effect in rats. Q J Stud Alcohol 29: 863-867.

Slawecki CJ, Hodge CW, Samson HH (1997). Dopaminergic and opiate agonists and antagonists differentially decrease multiple schedule responding maintained by sucrose/ethanol and sucrose. Alcohol 14: 281-294.

Spanagel R, Hölter SM, Allingham K, Landgraf R, Zieglgänsberger W (1996a). Acamprosate and alcohol: I. Effects on alcohol intake following alcohol deprivation in the rat. Eur J Pharmacol 305: 39-44. 
Spanagel R, Putzke J, Stefferl A, Schöbitz B, Zieglgänsberger W (1996b). Acamprosate and alcohol: II. Effects on alcohol withdrawal in the rat. Eur J Pharmacol 305: 45-50.

Stromberg MF, Mackler SA, Volpicelli JR, O’Brien CP (2001). Effect of acamprosate and naltrexone, alone or in combination, on ethanol consumption. Alcohol 23: 109-116.

Ulm RR, Volpicelli JR, Volpicelli LA (1995). Opiates and alcohol self-administration in animals. J Clin Psychiatry 56(Suppl 7): 5-14.

Wand GS (1989). Ethanol differentially regulates proadrenocorticotropin/endorphin production and corticosterone secretion in LS and SS lines of mice. Endocrinology 124: 518-526.
Weiss F, Mitchiner M, Bloom FE, Koob GF (1990). Free-choice responding for ethanol versus water in alcohol preferring (P) and unselected Wistar rats is differentially modified by naloxone, bromocriptine, and methysergide. Psychopharmacology 101: 178-186.

Whittington MA, Little HJ (1991). A calcium channel antagonist stereoselectively decreases ethanol withdrawal hyperexcitability but not that due to bicuculline in hippocampal slices. $\mathrm{Br} J$ Pharmacol 103: 1313-1320.

Wolffgramm J, Heyne A (1995). From controlled drug intake to loss of control: the irreversible development of drug addiction in the rat. Behav Brain Res 70: 77-94. 